\title{
$\mathrm{Pt}_{3} \operatorname{Re}$ Alloy Nanoparticles as Electrocatalysts for the
}

\section{Oxygen Reduction Reaction}

\author{
David Raciti ${ }^{\dagger}$, Joseph Kubal ${ }^{*}$, Cheng Ma ${ }^{\S}$, Michael Barclay, ${ }^{\#}$ Matthew Gonzalez ${ }^{\dagger}$, Miaofang \\ Chi $^{\S}$, Jeffrey Greeley, Karren L. More ${ }^{\S}$, Chao Wang ${ }^{\dagger, *}$
}

${ }^{\dagger}$ Department of Chemical and Biomolecular Engineering and ${ }^{\#}$ Department of Chemistry, Johns Hopkins University, 3400 N Charles Street, Baltimore, MD 21218.

${ }^{\S}$ Center for Nanophase Materials Sciences, Oak Ridge National Laboratory, Oak Ridge, TN 37831;

${ }^{\ddagger}$ School of Chemical Engineering, Purdue University, West Lafayette, IN 47907.

\begin{abstract}
Development of renewable energy technologies requires advanced catalysts for efficient electrical-chemical energy conversion reactions. Here we report the study of Pt-Re alloy nanoparticles as an electrocatalyst for the oxygen reduction reaction (ORR). An organic solution approach is developed to synthesize monodisperse and homogeneous $\mathrm{Pt}_{3} \mathrm{Re}$ alloy nanoparticles. Electrochemical studies show that these nanoparticles exhibit an improvement factor of 4 for the ORR compared to commercial Pt catalysts of similar particle size. Fundamental understanding of the structure-property relationship is established by Density Functional Theory (DFT) calculations, showing that an electronic modification (ligand effect) of the surface properties of Pt by subsurface Re accounts for the catalytic enhancement.
\end{abstract}


KEYWORDS. Platinum rhenium alloy nanoparticles, organic solution synthesis, electrocatalysts, ligand effect, oxygen reduction reaction

\section{Introduction}

Fed by hydrogen and oxygen gases, a fuel cell generates electricity from the hydrogen oxidation reaction at the anode and the oxygen reduction reaction (ORR) at the cathode. As it has water as the only by-product, the fuel cell is considered to be an environment-friendly technology. With hydrogen produced from water splitting with solar electricity and oxygen from air, it also represents a promising solution for energy sustainability.[1] However, the need for platinum $(\mathrm{Pt})$ as catalysts for the electrochemical reactions, especially the ORR, has limited large-scale applications of fuel cells.[2] The sluggish kinetics of the ORR leads to high overpotentials at the cathode, in the range of several hundred millivolts on Pt catalysts, and thereby large amounts of Pt are needed in fuel cell systems to achieve the desired power performance. The mass activity of commercial $\mathrm{Pt} / \mathrm{C}$ cathode catalysts is typically in the range of $0.1-0.2 \mathrm{~A} / \mathrm{mg}_{\mathrm{Pt}}(@ 0.9 \mathrm{~V})$, whereas $0.44 \mathrm{~A} / \mathrm{mg}_{\mathrm{Pt}}$ is targeted for the implementation of the proton exchange membrane fuel cell (PEMFC) in important energy segments such as transportation.[3, 4]

Many approaches have been studied to improve the performance of Pt electrocatalysts for the ORR, including optimization of Pt particle size and shape,[5-9] alloying Pt with non-noble transition metals,[10-18] and development of composite nanostructures[19-23]. Among these approaches, alloying has received extensive attention. In alloy catalysts the second metal could tailor the surface and catalytic properties of Pt through ensemble,[24] electronic (ligand)[25] and/or strain[13, 26] effects; these mechanisms could further be manipulated and controlled by varying the alloying element,[11, 27] composition,[28] shape[18], bulk[29-31] and surface 
structures[12, 32], in order to improve the catalytic activity and durability. The alloy catalysts investigated for the ORR so far are mainly bimetallic systems of Pt and $3 d$ transition metals such as $\mathrm{Fe}, \mathrm{Co}$, Ni and $\mathrm{Cu} .[10-15,18,23,28,31,33-35]$ Besides the observed catalytic enhancement, it has been noted in fundamental understanding that both ligand and strain effects are usually simultaneously present in these alloy catalysts. Density function theory (DFT) calculations show that both these two effects can cause shifts of surface Pt $d$ band center, which accounts for the reduced binding energies of oxygenated species $\left(\mathrm{O}_{\mathrm{ad}}\right.$ and $\left.\mathrm{OH}_{\mathrm{ad}}\right)$ and enhanced ORR activities.[16, 36-40] Except in a few particular cases where strain effect was exclusively depicted,[13] it has been challenging to experimentally separate the ligand and strain effects and the observed catalytic enhancement is typically a result of the cumulative effect of the two mechanisms.[38]

Conventionally alloy catalysts are prepared by impregnation methods that generally produce inhomogeneous catalysts of large particle size distribution.[41, 42] Although the average composition was usually correlated to the catalytic properties, elemental distribution is found to have remarkable effects on the local electronic structures and catalytic performance of alloy catalysts. $^{[43]}$ Over the past two decades substantial progress has been made on the organic solution synthesis of Pt-alloy nanoparticles.[14, 18, 44-47] Monodisperse and homogeneous colloidal nanoparticles of Pt-bimetallic alloys have been made by coupling the reduction of $\mathrm{Pt}$ salts with the decomposition of organometallic precursors of $3 d$ transition metals, or by subsequent addition of the metal salt precursors, in order to match the reduction and growth rates of Pt and the $3 d$ metal.[27] Organic surfactants employed in the synthesis can be removed by thermal treatment and the treated catalysts show high activities in electrochemical reactions.[48] 
Herein, we report the exploration of Pt-Re alloy as an electrocatalyst for the ORR. An organic solution approach was developed to synthesize monodisperse and homogeneous $\mathrm{Pt}_{3} \mathrm{Re}$ alloy nanoparticles, which were then supported on high-surface-area carbon black for electrochemical studies. The selection of Re was motivated in part by the previously reported high ORR activity of Pt-Re extended surfaces supported on Pd(111) single crystals.[49] Atomically resolved electron microscopy and elemental analysis were applied to depict the nanostructure of the alloy catalysts pre- and post-electrochemical studies. The characterized structures were further subjected to modelling by DFT calculations in order to establish the structure-property relationship for the alloy catalysts in the ORR.

\section{Material and Methods}

\subsection{Chemicals}

Metal precursors used in the syntheses were purchased from Strem Chemicals Inc. Organic solvents and ligands were purchased from Sigma Aldrich. All the chemicals were used as received.

\subsection{Synthesis}

In a typical synthesis of the $\mathrm{Pt}_{3} \operatorname{Re}$ nanoparticles, $0.1 \mathrm{mmol}$ of $\mathrm{Pt}(\mathrm{acac})_{2}$ and $0.1 \mathrm{mmol}$ of $\mathrm{Re}_{2}(\mathrm{CO})_{10}$ were dissolved in $10 \mathrm{ml}$ of dibenzyl ether with $1 \mathrm{ml}$ of oleylamine and $1 \mathrm{ml}$ of oleic acid. Under a constant stream of nitrogen, the resulting mixture was vigorously stirred and heated to $110{ }^{\circ} \mathrm{C}$. After 20 minutes, $0.1 \mathrm{~g}$ of tungsten carbonyl $\left(\mathrm{W}(\mathrm{CO})_{6}\right)$ was added and the solution was then brought to $200^{\circ} \mathrm{C}$. After 30 minutes it was cooled down to the room temperature. The product was collected by adding ethanol and centrifuge, and then re-dispersed in hexane. 
For catalyst preparation, the as-synthesized $\mathrm{Pt}_{3} \mathrm{Re}$ nanoparticles were mixed with carbon black (Ketjenblack, $\sim 900 \mathrm{~m}^{2} / \mathrm{g}$ ) in a 1:1 mass ratio in toluene and sonicated for $1 \mathrm{~h}$. The mixture was then dried out in air at $\sim 80^{\circ} \mathrm{C}$. The organic surfactants were removed by annealing at $185^{\circ} \mathrm{C}$ in air.[48] Further annealing at $400^{\circ} \mathrm{C}$ was performed in a tube furnace with a flow of forming gas $\left(\mathrm{N}_{2}+5 \% \mathrm{H}_{2}\right)$.

\subsection{Materials Characterization}

Low resolution transmission electron microscopy (TEM) imaging was performed on a $120 \mathrm{kV}$, FEI Tecnai 12 TWIN microscope. A 300 kV, field emission Phillips CM300-FEG was used for high-resolution TEM (HRTEM) imaging. X-ray diffraction (XRD) patterns were collected on a PANalytical X'Pert ${ }^{3}$ Powder X-Ray Diffractometer equipped with a $\mathrm{Cu} \mathrm{K} \alpha$ radiation source $(\lambda=0.15406)$. High-angle annular dark field scanning transmission electron microscopy (HAADF-STEM) and energy-dispersive X-ray spectroscopy (EDS) characterization of individual nanoparticles, including spectra collected to produce the elemental maps, were conducted on a JEOL 2200FS TEM/STEM equipped with a CEOS aberration (probe) corrector and a Bruker-AXS X-Flash 5030 silicon drift X-ray detector. The microscope was operated at $200 \mathrm{kV}$, and the electron beam size was $\sim 0.7 \AA$ for imaging and $\sim 2 \AA$ for EDS analysis (probe current $~ 400 \_500$ pA). Fourier Transformed Infrared Spectroscopy (FTIR) was performed on the nanoparticles with a Varian 640 Spectrophotometer.

X-ray photoelectron spectroscopy (XPS) measurements were obtained using the $\mathrm{Mg} \mathrm{K} \alpha \mathrm{X}$ ray source on a PHI 5600 Multi-technique photoelectron spectrometer. The X-ray source was operated at $15 \mathrm{kV}, 300 \mathrm{~W}$ and a pass energy of $5.85 \mathrm{eV}$ was used to sample ejected photoelectrons from the $\mathrm{Pt}(4 \mathrm{f})$ and $\operatorname{Re}(4 \mathrm{f})$ regions. Peak fitting of the $\operatorname{Re}(4 \mathrm{f})$ region was performed using the CasaXPS software and a Gaussian-Lorentzian (30) line-shape. 


\subsection{Electrochemical Studies}

The ORR activities were measured with a rotational disk electrode (RDE, $5 \mathrm{~mm}$ diameter) setup in a three compartment electrochemical cell and an Autolab 302 potentiostat. A saturated $\mathrm{Ag} / \mathrm{AgCl}$ electrode and a gold wire were used as reference and counter electrodes, respectively. A solution of $0.1 \mathrm{M} \mathrm{HClO}_{4}$ was used as electrolyte. For electrode preparation, the carbon supported catalysts were dispersed in $5 \%$ isopropanol/ $\mathrm{H}_{2} \mathrm{O}$ at $1 \mathrm{mg} / \mathrm{ml}$ by sonication. A suspension of 15-20 $\mu \mathrm{l}$ was deposited onto the RDE surface and allowed to dry in air. Electrochemical surface areas (ECSAs) were estimated by integration of the under-potentially deposited hydrogen $\left(\mathrm{H}_{\text {upd }}\right)$ region of the cyclic voltammogram $(\mathrm{CV})$. The ECSAs were used to normalize the kinetic current densities, that is, specific activity. All potentials discussed in the text are given against the reversible hydrogen electrode (RHE) with $i R$ drop correction.[50]

\subsection{Calculation}

DFT calculations were performed to determine the $\mathrm{Pt}_{3} \mathrm{Re}$ structure under reaction conditions. Spin polarized ground state energies of the various $\mathrm{Pt}_{3} \mathrm{Re}$ structures were calculated with the Vienna Ab-initio Simulation Package (VASP), a periodic DFT code utilizing a plane wave basis set.[51, 52] Core electrons were approximated using projector augmented waves (PAW) formalism to increase calculation efficiency. First order Methfessel-Paxton smearing was utilized to calculate the electronic occupancies with a smearing width of $0.2 \mathrm{eV}$. The RPBE exchangecorrelation functional was employed[53] with a $340 \mathrm{eV}$ energy cutoff. This set of parameters has been used extensively to study the ORR.[16, 54] The structures were relaxed until the forces on each atom were less than $0.05 \mathrm{eV} / \AA$.

A $\mathrm{Pt}_{3} \mathrm{X}(111)$ single crystal fcc alloy model was used to study the various $\mathrm{Pt}_{3} \mathrm{Re}$ structures. The Pt lattice constant was found to be $3.99 \AA$, while the $\mathrm{Pt}_{3} \mathrm{Re}$ lattice constant was found to be 
slightly smaller, at $3.96 \AA$; both are comparable to literature values.[55] The surfaces were modeled with five layer slabs with a vacuum region equal to six equivalent slab layers. $(2 \times 2)$ surface unit cells were employed. The positions of the bottom two layers of the slabs were fixed during the simulation, and all other layers and adsorbates were fully relaxed. The surface structures were modeled as pure Pt skins with thicknesses of one to four layers, with the remaining subsurface layers adopting the bulk $\mathrm{Pt}_{3} \mathrm{Re}$ structure. In addition to the calculations on the $(2 \times 2)$ cells, a $(2 \times 4)$ configuration with a single layer Pt skin and a reduced (from 1:3 to 1:7 $\mathrm{Re}: \mathrm{Pt}$ ) amount of $\mathrm{Re}$ in the second layer was tested to evaluate the effect of the subsurface $\mathrm{Re}$ coverage on the results. A negligible difference in adsorption energetics was found, and all skin results are therefore reported on the $(2 \times 2)$ unit cell. In addition, a larger unit cell was used to modelthe $\mathrm{ReO}_{\mathrm{x}}$ adatom on the surface (see Supplementary Materials for details). A (8x8x1) Monkhorst-Pack $k$-point grid was used for the $(2 \mathrm{x} 2)$ structures, while a $(8 \mathrm{x} 4 \mathrm{x} 1) \mathrm{k}$-point grid was used on the larger $(2 \times 4)$ cell. Binding energies of $\mathrm{O}, \mathrm{OH}$, and $\mathrm{OOH}$ were calculated on all surface structures.

Free energies were calculated as a function of electrode potential with respect to a water reference, which was employed to avoid the use of diatomic oxygen as a reference due to the difficulty in DFT of accurately calculating the ground state energy of $\mathrm{O}_{2}$.[56] Barriers for the elementary ORR reactions are generally believed to be dominated by the thermodynamics of the reactions since the protonation overbarriers are small.[57] Thus, the step with the highest thermodynamic barrier can be considered to be the rate limiting step, as dictated by Sabatier analysis.[58] A full description of the calculation of the free energy is given in the supporting information.[54] 


\section{Results and Discussion}

$\mathrm{Pt}_{3} \mathrm{Re}$ nanoparticles were synthesized by coupling the reduction of platinum acetylacetonate, $\operatorname{Pt}(\mathrm{acac})_{2}$, with the decomposition of rhenium carbonyl $\left(\operatorname{Re}_{2}(\mathrm{CO})_{10}\right)$ (Fig. 1a). In the synthesis $\mathrm{W}(\mathrm{CO})_{6}$ was used to initiate the reduction of $\mathrm{Pt}(\mathrm{acac})_{2}$, as indicated by immediate change of the solution color from transparent to dark black after the addition. The obtained nanoparticles have an average size of $6 \mathrm{~nm}$ (Fig. 1b). The atomic ratios of Pt and Re were determined to be $73 \%$ and $27 \%$ by EDS, respectively (Fig. S1). HRTEM images show lattice fringes with a spacing of 0.22 $\mathrm{nm}$, which can be assigned to the (111) planes of face-cantered cubic (fcc) crystal of $\mathrm{Pt}_{3} \mathrm{Re}$ alloy (Fig. 1c). EDX analysis was performed on the as-synthesized $\mathrm{Pt}_{3} \mathrm{Re}$ nanoparticles and no tungsten was detected, indicating $\mathrm{W}(\mathrm{CO})_{6}$ may only alter the chemistry involved in the nucleation and growth process instead of adding $\mathrm{W}$ to the alloy. This phenomenon is consistent with the previous report on using $\mathrm{W}(\mathrm{CO})_{6}$ to control the nucleation and growth of $\mathrm{Pt}_{3} \mathrm{Ni}$ nanoparticles.[18] Later on it was further postulated that the role of $\mathrm{W}(\mathrm{CO})_{6}$ is to generate $\mathrm{CO}$ in situ, which could serve as both a reducing agent that alters the nucleation and growth and a capping ligand that control the size and shape of the nanoparticles.[18, 59]

$\mathrm{Pt}_{3} \mathrm{Re}$ nanoparticles from the organic solution synthesis were supported on carbon black by the colloidal deposition method.[60] The surfactants employed in the synthesis, oleylamine and oleic acid, were removed by thermal annealing in air at $185^{\circ} \mathrm{C}$.[48] The obtained catalysts have a uniform distribution of nanoparticles supported on carbon (Fig. 2a). To confirm the removal of organic content, Fourier transform infrared spectroscopy (FTIR) was used to track the vibrational peaks of the surfactant molecules for the nanoparticles in the absence of carbon (Fig. S2). The spectrum for the as-synthesized nanoparticles show the characteristic peaks of the oleic group, including the two strong peaks at $2800-3000 \mathrm{~cm}^{-1}$ for the symmetric and asymmetric stretching 
of $-\mathrm{CH}_{2}$ or $-\mathrm{CH}_{3}$ groups and the stretching mode of $=\mathrm{C}-\mathrm{H}$ at $3004 \mathrm{~cm}^{-1}$. The absence of the peak associated with $-\mathrm{NH}_{2}$ at $\sim 3300 \mathrm{~cm}^{-1}$ was due to the binding of oleylamine to the nanoparticles through the amine group. These peaks were found to disappear in the spectrum for the nanoparticles after annealing at $185^{\circ} \mathrm{C}$, demonstrating that this treatment could be used to remove the surfactants in the nanocatalysts.

Besides removing the surfactants, the thermal treatment in air also induced oxidation of Re in the nanoparticles. XPS studies indicate the presence of rhenium oxide in the $185^{\circ} \mathrm{C}$ annealed $\mathrm{Pt}_{3} \mathrm{Re} / \mathrm{C}$. In the XPS spectra shown in Fig. 2d (see Fig. S3 for deconvolution), the two peaks at 45 and $48 \mathrm{eV}$ can be assigned to the $\mathrm{f}$ orbitals of $\mathrm{Re}^{2+}$ and/or $\mathrm{Re}^{3+}$, respectively, which are indistinguishable owing to the limited resolution; the peaks at 41 and $43 \mathrm{eV}$ are corresponding to the $4 \mathrm{f}_{7 / 2}$ and $4 \mathrm{f}_{5 / 2}$ orbitals of metallic Re. About $54 \%$ of Re in the alloy nanoparticles was oxidized according to the fitting for the XPS spectra, which indicates not only Re atoms on the surface, but also subsurface ones are likely oxidized through this process. In contrast, no oxidation was observed for Pt in the alloy nanoparticles after the annealing in air (Fig. S4).

To reduce the $\mathrm{ReO}_{x}$ and ensure alloy homogeneity, the $\mathrm{Pt}_{3} \mathrm{Re} / \mathrm{C}$ catalyst was further annealed at $400^{\circ} \mathrm{C}$ in a forming gas $\left(\mathrm{N}_{2}+5 \% \mathrm{H}_{2}\right)$. This temperature was selected to avoid substantial particle aggregation and agglomeration at higher temperatures,[61] which was confirmed by TEM images of the catalyst after the annealing (Fig. 2b). XPS shows the $\mathrm{ReO}_{x}$ content was substantially reduced by this treatment (Fig. 2 d). It was found that $<20 \%$ of Re remained in the oxide state, which is probably due to the re-oxidation of surface Re atoms in air. Besides reducing rhenium oxide, the annealing also improved the crystallinity of the nanoparticles. Fig. 2e shows the XRD patterns recorded for the $\mathrm{Pt}_{3} \mathrm{Re} / \mathrm{C}$ catalysts after the various treatments, in comparison with the commercial $\mathrm{Pt} / \mathrm{C}$ catalyst (Tanaka, $5 \mathrm{~nm}$ ) used as control in the 
electrochemical studies. The peaks at $40^{\circ}, 46^{\circ}, 67^{\circ}$ and $81^{\circ}$ can be assigned to the (111), (200) and (220) and (311) planes of fcc Pt or Pt alloys. In particular, it is noticed that no significant shift in the peaks were observed by $\mathrm{XRD}$ for $\mathrm{Pt}_{3} \mathrm{Re}$ compared to $\mathrm{Pt}$, indicating that strain is not significant in this bimetallic alloy. This is consistent with the previously reported phase diagram for this alloy.[62] Additional observation is that the crystalline size increased from $3.5 \mathrm{~nm}$ for the as-synthesized nanoparticles to 4.4 and $5.3 \mathrm{~nm}$ for the 185 and $400^{\circ} \mathrm{C}$ annealed catalysts, respectively, estimated by using the Scherrer equation. The improvement in crystallinity was further confirmed by atomically resolved TEM images for the $400^{\circ} \mathrm{C}$ annealed $\mathrm{Pt}_{3} \mathrm{Re} / \mathrm{C}$ catalyst (Fig. 2c), which is believed to be beneficial for the ORR catalysis.[61]

Electrochemical performance of the $\mathrm{Pt}_{3} \mathrm{Re} / \mathrm{C}$ catalysts was studied by the rotating disk electrode (RDE) method and compared to the state-of-the-art commercial Pt/C (Tanaka, $5 \mathrm{~nm}$ ). Fig. 3a shows the cyclic voltammograms (CVs) recorded for the three catalysts. Both the 185 and $400^{\circ} \mathrm{C}$ annealed $\mathrm{Pt}_{3} \mathrm{Re} / \mathrm{C}$ catalysts exhibit substantially supressed $\mathrm{H}_{\text {upd }}$ peaks at $E<0.4 \mathrm{~V}$ compared to $\mathrm{Pt} / \mathrm{C}$, probably owing to the altered surface properties of the alloy catalysts[63] considering the small difference in particle size $(6$ vs. $5 \mathrm{~nm})$. The Pt-OH peaks $(0.8-0.9 \mathrm{~V})$ of the alloy catalysts are also supressed compared to $\mathrm{Pt} / \mathrm{C}$, and positively shifted by about 30 and 40 $\mathrm{mV}$ for the 185 and $400^{\circ} \mathrm{C}$ annealed ones, respectively. Such positive shifts are indication of the reduced strengths of $\mathrm{Pt}-\mathrm{OH}$ binding, which are usually associated with enhanced ORR activities.[63] Consistently, the polarization curves show similar positive shifts, from which the half-wave potentials read at 0.92 and $0.93 \mathrm{~V}$ for the two alloy catalysts, versus $0.89 \mathrm{~V}$ for $\mathrm{Pt} / \mathrm{C}$ (Fig. 3b). At $0.9 \mathrm{~V}$, specific activities of the 185 and $400^{\circ} \mathrm{C}$ annealed $\mathrm{Pt}_{3} \mathrm{Re} / \mathrm{C}$ catalysts reach 1.3 and $2.0 \mathrm{~mA} / \mathrm{cm}^{2}$, corresponding to improvement factors of $\sim 3$ and 4 versus $\mathrm{Pt} / \mathrm{C}$, respectively 
(Fig. 3c and 3d). In line with those results the two alloy catalysts have mass activities of 0.30 and $0.51 \mathrm{~A} / \mathrm{mg}$ which are respectively 2.2 and 3.6 times of the activity of Pt/C (Fig. 3e).

To develop a fundamental understanding of the catalytic enhancement in the Pt-Re alloy catalysts, DFT calculations were used to determine the binding energies of the various ORR intermediates on the Pt and alloy surfaces, based on which full free energy diagrams were constructed (Fig. 4) for the various structures examined. The associative mechanism was chosen for study, as this ORR mechanism has been found to exhibit the most favourable energetics on Pt-containing alloys.[36, 57]

A structural model with rhenium oxide on the Pt surface was initially considered, given the observation of surface $\mathrm{ReO}_{x}$ by XPS (Fig. 2d). First, mechanisms were considered in which the ORR intermediates react at the boundary between the oxidized Re and the alloy substrate. However, results from this model strongly suggest that the $\mathrm{Pt}-\mathrm{O}$ binding is reduced by a large amount, owing to the repulsive effect between the $\mathrm{ReO}_{x}$ and $\mathrm{O}_{\text {ad }}$, actually leading to lower ORR activities than the corresponding clean surfaces (see the Supporting Information). It was therefore concluded that the reaction must occur on a Pt-skin type of surface in the absence of any $\mathrm{ReO}_{x}$ units on the surface. A variety of such models were considered, including Pt skins of varying thicknesses and subsurface Re coverages, and results for selected structures are presented in Table 1 and Fig. 4. We note, in passing, that these conclusions, obtained on bulk $\mathrm{Pt}_{3} \mathrm{Re}$ alloy surfaces, are not directly comparable to the corresponding results of Zhang et al., who studied a single monolayer of $\mathrm{Pt}$ and $\mathrm{Re}$ on a $\mathrm{Pd}(111)$ substrate.[49]

On the monolayer Pt skin, the binding energy of atomic oxygen is unusually weak, and the rate determining step is therefore the conversion of $\mathrm{OH}^{*}$ to water. On the two-layer skin, the thermodynamics of the $\mathrm{O}^{*}$ to $\mathrm{OH}^{*}$ and $\mathrm{OH}^{*}$ to water steps are roughly balanced, and the rate 
limiting barrier is even lower than on the single layer skin. The results of the three layer skins and the pure Pt surface are similar to one another, and the energetics for a pure Pt surface that has been strained to match the lattice constant of $\mathrm{Pt}_{3} \mathrm{Re}$ also show very little difference compared to an unstrained pure Pt surface. We note that these adsorption energetics show small deviations from the well-known scaling relationships between oxygen-containing adsorbate binding energies on transition metal surfaces,[64] necessitating the use of the full free energy diagrams to estimate activities, as opposed to simplified volcanos based only on oxygen binding energies.[16] These results imply that the promotional effects of one- and two-monolayer skins are due primarily to ligand effects from the subsurface Re atoms, while strain effects play a relatively small role. This finding is also consistent with the observation of similar lattice constants between the $\mathrm{Pt}$ and $\mathrm{Pt}_{3} \mathrm{Re}$ catalysts by XRD (Fig. 2e). Overall, the surfaces with one and two Pt skin layers were found to possess the most promising ORR activities compared to the other models examined.

The simulation results have inspired us to take a closer look at the atomic structures of the alloy nanocatalysts, in particular after the electrochemical measurements in order to derive the structure information during the ORR. Fig. 5 shows the results of element mapping for the $400^{\circ} \mathrm{C}$ annealed $\mathrm{Pt}_{3} \mathrm{Re} / \mathrm{C}$ catalysts prior- and post-electrochemical studies. The as-prepared alloy catalyst possesses uniform distribution of Pt and Re elements throughout the nanoparticle (Fig. 5 $\mathrm{a}$-c), in the absence of clear evidence for the formation of Pt-skin. The content of Re substantially reduced to $12 \%$ after the electrochemical studies for the ORR, producing a Pt-rich shell (Fig. $5 \mathrm{~d}-\mathrm{f}$ ). This suggests that $\mathrm{Re}\left(\right.$ or $\mathrm{ReO}_{x}$ ) is not stable in the ORR conditions, and the $\mathrm{Re}$ species in the near-surface regions of the $\mathrm{Pt}_{3} \mathrm{Re}$ nanoparticles was leached out under the electrochemical conditions.[33] Combining the element mapping and the simulation, it can be 
seen that the enhanced catalytic activities of the Pt-Re alloy catalysts are associated with the structure with a Pt-rich shell of which the surface properties are modified by the subsurface Re species via the ligand effect.

Finally, the $\mathrm{Pt}_{3} \mathrm{Re} / \mathrm{C}$ catalysts were found to be stable under the electrochemical conditions mimicking the running conditions of PEMFCs. Figure 6 summarizes the electrochemical results for the $\mathrm{Pt}_{3} \mathrm{Re} / \mathrm{C}$ catalysts before and after 4,000 potential cycles between 0.6 and $1.1 \mathrm{~V}$. Both the 185 and $400^{\circ} \mathrm{C}$ annealed catalysts had minor losses in specific $(<20 \%)$ and mass $(<25 \%)$ activities, indicating the Pt-rich shell that formed under the electrochemical conditions was able to protect the Re species inside the alloy nanoparticles from further leaching out.

\section{Conclusions}

We explored Pt-Re alloy nanoparticles as electrocatalysts for the ORR. An organic solution approach was developed to synthesize monodisperse and homogeneous $\mathrm{Pt}_{3} \mathrm{Re}$ alloy nanoparticles. These nanoparticles were supported on carbon black, with the organic surfactants removed by thermal treatment in air. Electrochemical studies show that the alloy catalysts are highly active for the ORR, reaching improvement factors of $3-4$ compared to Pt catalysts of similar particle sizes. By combining DFT calculations and atomically resolved element mapping, the catalytic enhancement was interpreted and ascribed to the nanostructure with Pt-rich shell where the subsurface Re electronically modified the surface properties (a ligand effect) and reduced the binding strength of $\mathrm{Pt}-\mathrm{OH}$. Our work depicted the role of ligand effect in modifying the surface properties and enhancing the catalytic activity of certain Pt-based alloy catalysts. Based on the findings reported here, it is plausible to design alloy catalysts that integrates the 
ligand and strain effects in a rational way (such as a trimetallic system involving $\mathrm{Pt}$, $\mathrm{Re}$ and another transition metal[65, 66]) for further catalytic activity and durability enhancement.

\section{ASSOCIATED CONTENT}

Supplementary Material. More details about characterization and computation are available in the Supporting Material. This material is available free of charge via the Internet at http://www.sciencedirect.com.

\section{AUTHOR INFORMATION}

\section{Corresponding Author}

*Email: chaowang@jhu.edu

\section{Author Contributions}

The manuscript was written through contributions of all authors. All authors have given approval to the final version of the manuscript.

\section{ACKNOWLEDGMENT}

This work was supported by the start-up fund and E2SHI Seed Grant from Johns Hopkins University, the Ralph E. Powe Jr. Faculty Enhancement Award (ORAU), and the National Science Foundation (CBET-1437219). The microscopic work at Oak Ridge National Laboratory was performed at the Center for Nanophase Materials Sciences (CNMS), which is a user facility supported by the U.S. Department of Energy, Office of Science. J.G also acknowledges support through an Early Career grant from the Department of Energy, Office of Science, Office of Basic Energy Sciences, Chemical Sciences Division. Computational support through the National 
Energy Research Scientific Computing Center (NERSC) is gratefully acknowledged. The authors thank Prof. Howard Fairbrother for help on XPS analysis. 
(a)
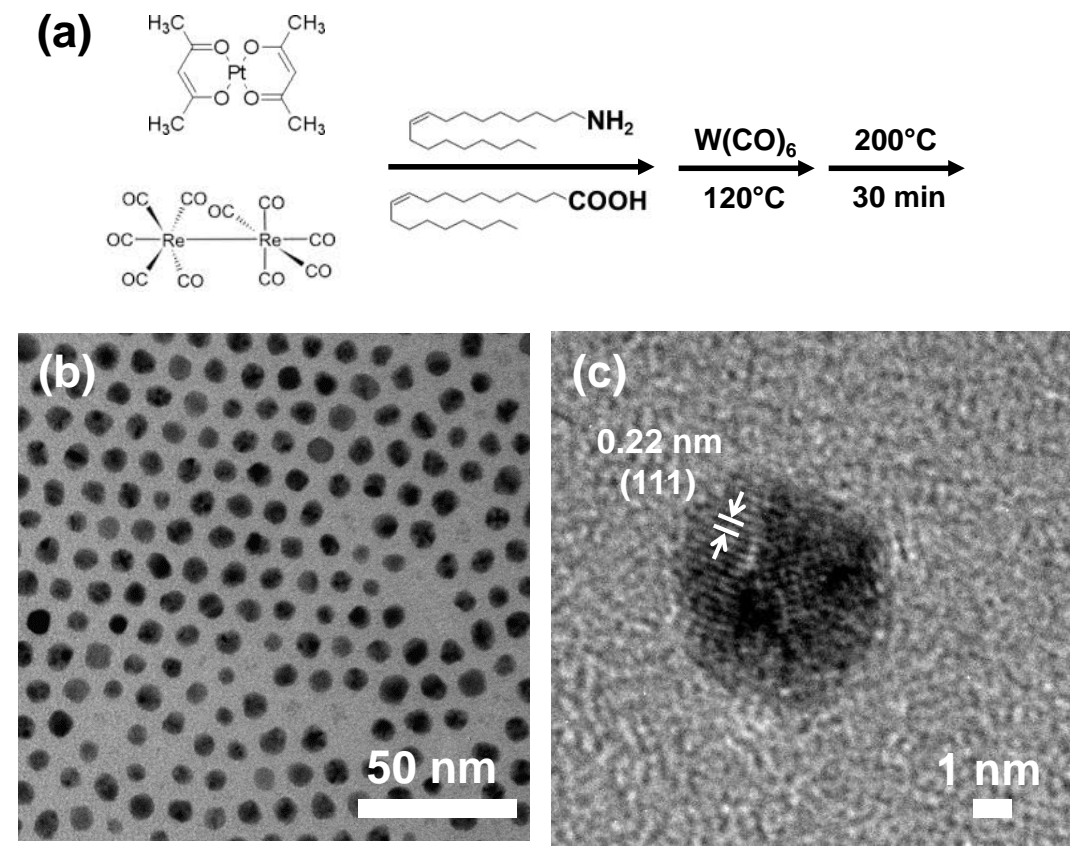

Figure 1. (a) Schematic illustration of the synthetic route for $\mathrm{Pt}_{3} \mathrm{Re}$ alloy nanoparticles. (b) TEM and (c) HRTEM images of as-synthesized $\mathrm{Pt}_{3} \mathrm{Re}$ nanoparticles. 

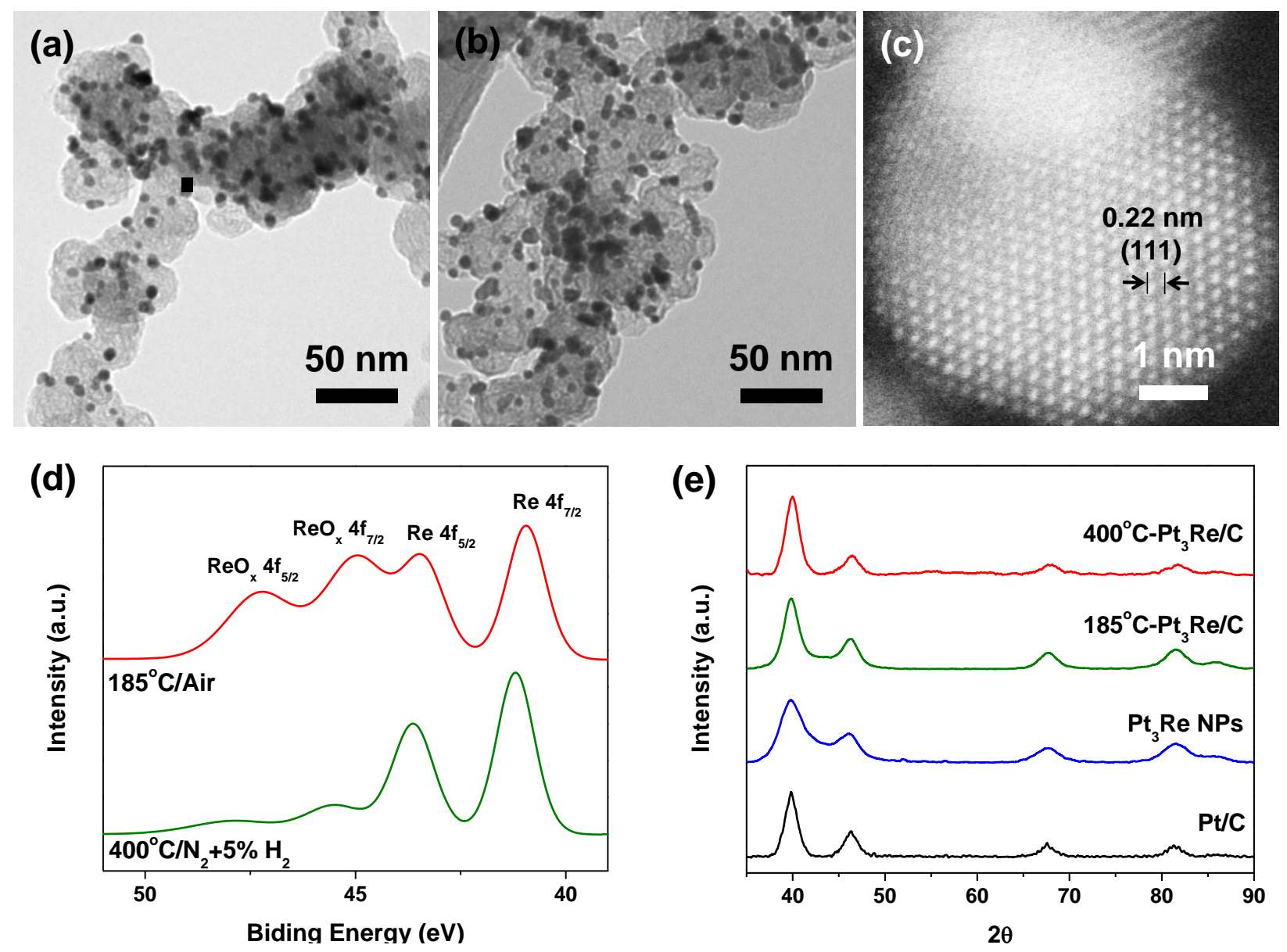

Figure 2. Representative TEM images of the $\mathrm{Pt}_{3} \mathrm{Re} / \mathrm{C}$ catalysts annealed at (a) $185^{\circ} \mathrm{C}$ and (b) $400^{\circ} \mathrm{C}$. (c) HAADF-STEM image of a Pt ${ }_{3}$ Re nanoparticle for the catalyst shown in (b). (d) XPS spectra and (e) XRD patterns collected for the various nanoparticles/catalysts involved in this study. 

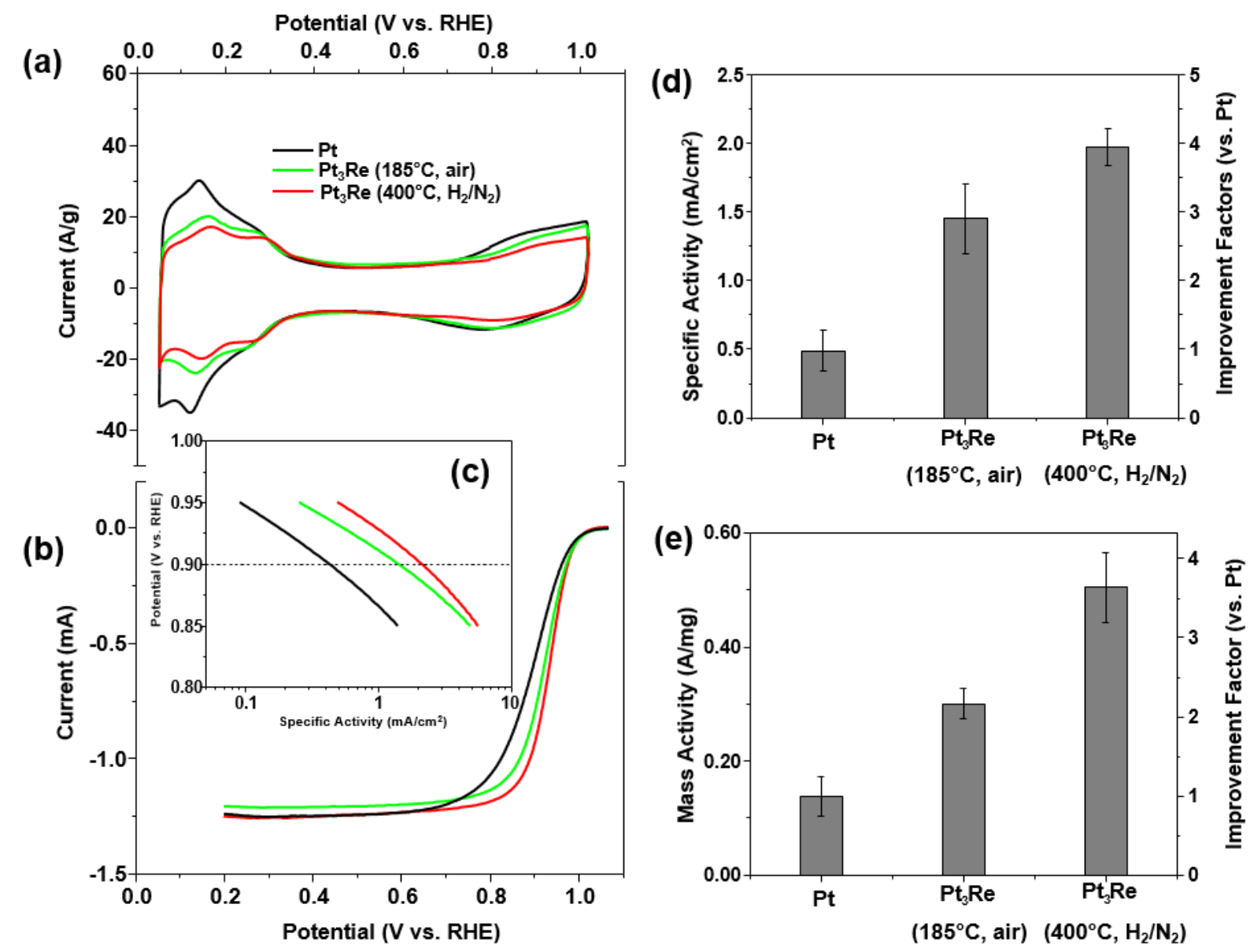

Figure 3. Summary of the results from electrochemical studies on the $\mathrm{Pt}_{3} \mathrm{Re} / \mathrm{C}$ catalysts for the ORR. (a) CVs recorded at $50 \mathrm{mV} / \mathrm{s}$ in Ar saturated $0.1 \mathrm{M} \mathrm{HClO}_{4}$. (b) Polarization curves recorded at $20 \mathrm{mV} / \mathrm{s}$ with the electrolyte saturated with $\mathrm{O}_{2}$. (c) Tafel plots of the kinetic current densities depending on the electrode potential. (d) Specific activities and (e) mass activities of the $\mathrm{Pt}_{3} \mathrm{Re} / \mathrm{C}$ catalysts in comparison with commercial $\mathrm{Pt} / \mathrm{C}$, where the plotted values are averages of the results from a minimum of three independent measurements. The total metal loadings (Pt $+\mathrm{Re}$ ) for both $\mathrm{Pt}_{3} \mathrm{Re}$ catalysts were $7.5 \mathrm{ug}$, and for the $\mathrm{Pt} / \mathrm{C}$ it was $7.5 \mathrm{ug}$ for a $5 \mathrm{~mm}$ glassy carbon disk. 


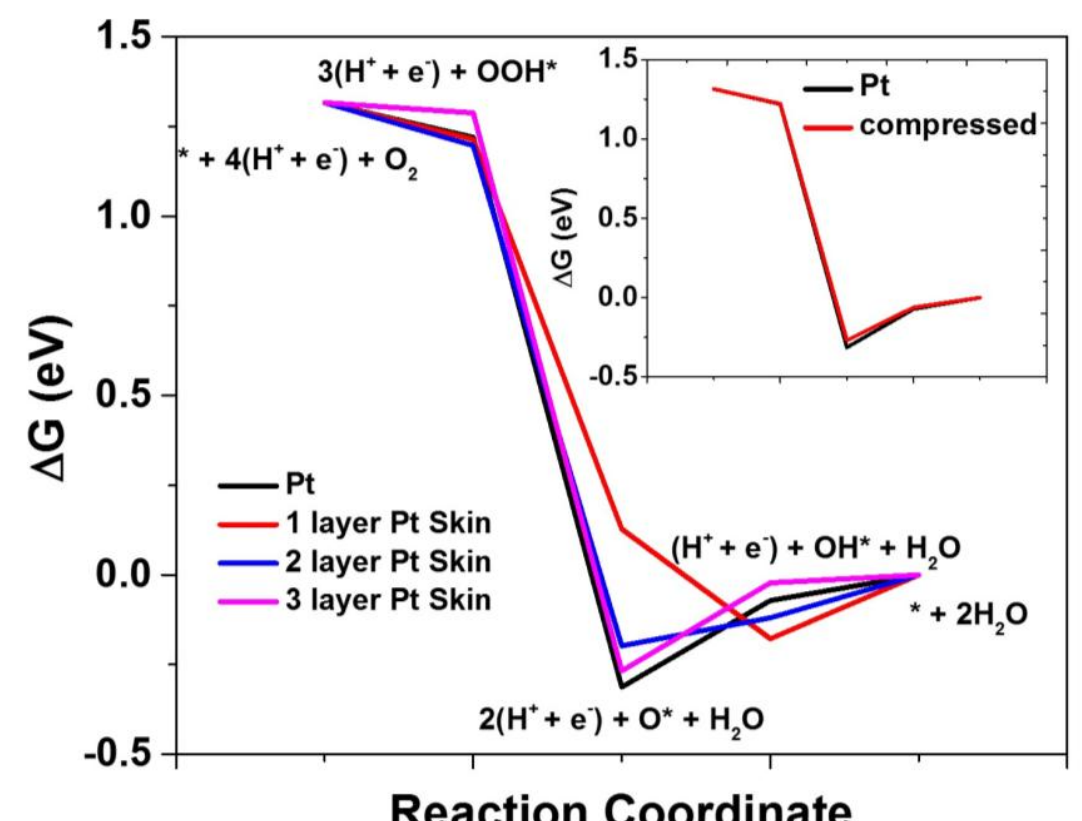

Figure 4. Reaction coordinate at $\mathrm{U}=0.9 \mathrm{~V}$ (RHE. The two-layer Pt skin structure has the lowest rate-limiting thermodynamic barrier. The inset shows that the compressed Pt surface (to match the lattice constant of $\mathrm{Pt}_{3} \mathrm{Re}$ ) and the uncompressed $\mathrm{Pt}$ surface have very similar thermodynamics, indicating that the electronic/ligand component of the skinned surfaces contributes more to the change in binding than the strain. 


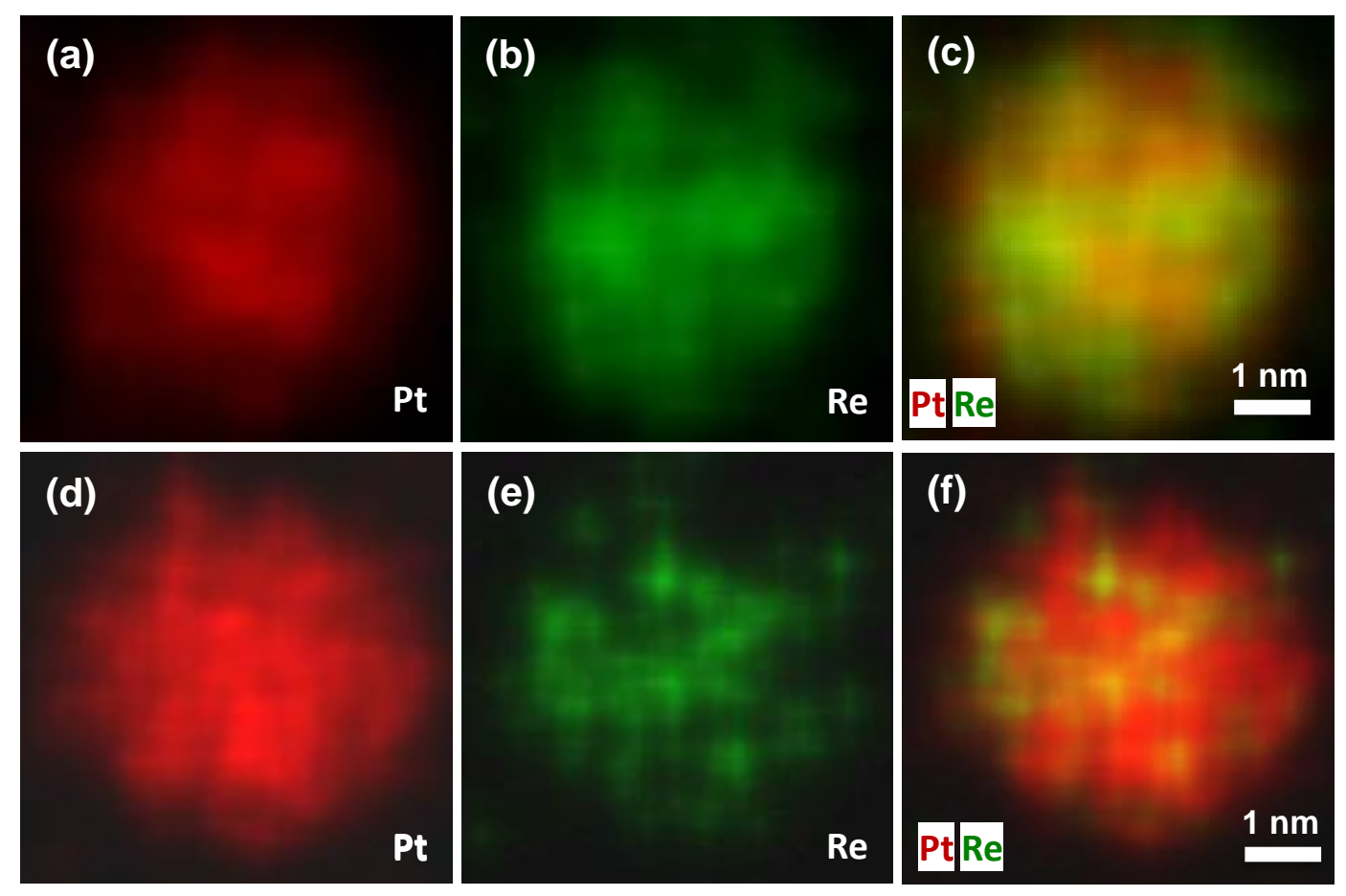

Figure 5. Element maps depicted by STEM-based EDS for the $400^{\circ} \mathrm{C}$ annealed $\mathrm{Pt}_{3} \mathrm{Re} / \mathrm{C}$ catalysts (a-c) before and (d-f) after electrochemical studies. 
(a)

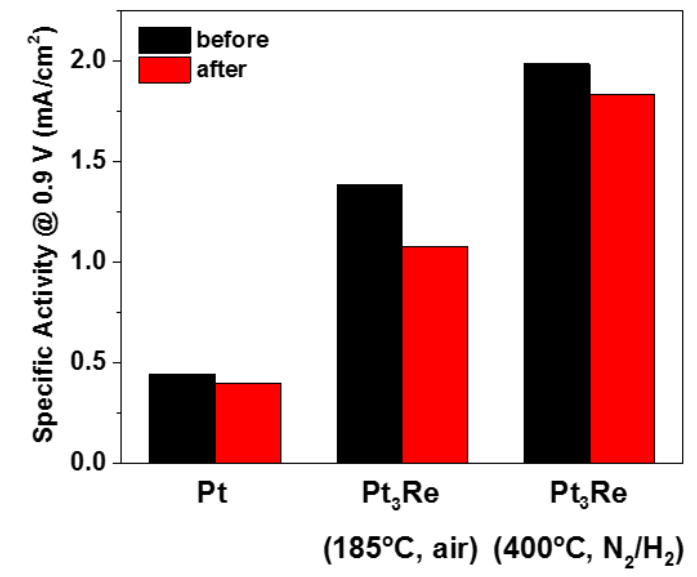

(b)

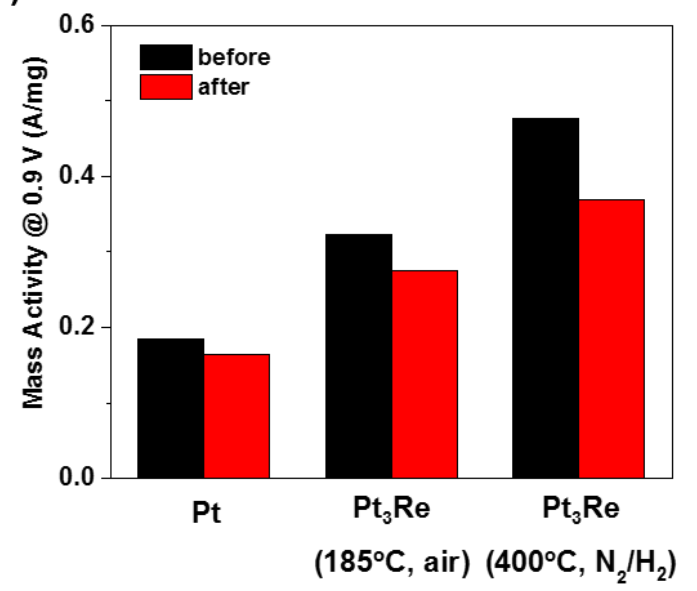

Figure 6. Durability studies for the $\mathrm{Pt}_{3} \mathrm{Re} / \mathrm{C}$ catalysts in comparison to $\mathrm{Pt} / \mathrm{C}$ for the ORR: (a) specific activities and (b) mass activities measured at $0.9 \mathrm{~V}$ before (black) and after (red) 4,000 potential cycles between 0.6 and $1.1 \mathrm{~V}$ (vs. RHE) in $0.1 \mathrm{M} \mathrm{HClO}_{4}$ saturated with $\mathrm{O}_{2}$. 
Table 1. Selected structures examined and the effective barrier associated with the ORR reaction at a potential of $0.9 \mathrm{~V}$ and $\mathrm{pH}=0$. The effective barrier is defined as the free energy change of the elementary step with the highest thermodynamic energy barrier, as determined by the DFT calculations. It should be noted that the difference in the effective barrier between the unstrained and compressed Pt surfaces is small. This implies that the electronic contribution from the addition of Re has a bigger impact in lowering the overall barrier than the strain contribution. It is seen that the one and two layer Pt skins offer an increased activity towards the ORR compared to the conventional Pt catalyst.

\begin{tabular}{lc} 
Structure & $\begin{array}{c}\text { Effective } \\
\text { Barrier }(\mathrm{eV})\end{array}$ \\
\hline Pt Surface & 0.24 \\
Compressed Pt Surface & 0.22 \\
1 Layer Pt Skin & 0.18 \\
2 Layer Pt Skin & 0.12 \\
3 Layer Pt Skin & 0.24
\end{tabular}




\section{REFERENCES}

[1] W. Vielstich, A. Lamm, H.A. Gasteiger, Handbook of fuel cells: fundamentals, technology, and applications, Wiley, Hoboken, N.J., 2003.

[2] B. Richter, D. Goldston, G. Crabtree, L. Glicksman, D. Goldstein, D. Greene, D. Kammen, M. Levine, M. Lubell, M. Savitz, D. Sperling, F. Schlachter, J. Scofield, J. Dawson, Rev. Mod. Phys., 80 (2008) S1-S107.

[3] H.A. Gasteiger, S.S. Kocha, B. Sompalli, F.T. Wagner, Appl. Catal. B-Environ., 56 (2005) 935.

[4] M.K. Debe, Advanced Cathode Catalysts and Supports for PEM Fuel Cells. 2012 DOE Hydrogen and Fuel Cells Program Annual Merit Review.

[5] K. Kinoshita, J. Electrochem. Soc., 137 (1990) 845-848.

[6] M.H. Shao, A. Peles, K. Shoemaker, Nano Lett., 11 (2011) 3714-3719.

[7] C. Wang, H. Daimon, T. Onodera, T. Koda, S.H. Sun, Angew. Chem. Int. Ed., 47 (2008) 3588-3591.

[8] C.M. Sanchez-Sanchez, J. Solla-Gullon, F.J. Vidal-Iglesias, A. Aldaz, V. Montiel, E. Herrero, J. Am. Chem. Soc., 132 (2010) 5622-5623.

[9] Z.M. Peng, H. Yang, Nano Today, 4 (2009) 143-164.

[10] V.R. Stamenkovic, B. Fowler, B.S. Mun, G.F. Wang, P.N. Ross, C.A. Lucas, N.M. Markovic, Science, 315 (2007) 493-497.

[11] V.R. Stamenkovic, B.S. Mun, M. Arenz, K.J.J. Mayrhofer, C.A. Lucas, G.F. Wang, P.N. Ross, N.M. Markovic, Nat. Mater., 6 (2007) 241-247.

[12] C. Wang, M.F. Chi, D.G. Li, D. Strmenik, D. van der Vliett, G.F. Wang, V. Komanicky, K.C. Chang, A.P. Paulikas, D. Tripkovic, J. Pearson, K.L. More, N.M. Markovic, V.R. Stamenkovic, J. Am. Chem. Soc., 133 (2011) 14396-14403.

[13] P. Strasser, S. Koh, T. Anniyev, J. Greeley, K. More, C.F. Yu, Z.C. Liu, S. Kaya, D. Nordlund, H. Ogasawara, M.F. Toney, A. Nilsson, Nature Chem., 2 (2010) 454-460.

[14] J.B. Wu, L. Qi, H.J. You, A. Gross, J. Li, H. Yang, J. Am. Chem. Soc., 134 (2012) 1188011883.

[15] S.I. Choi, S.F. Xie, M.H. Shao, J.H. Odell, N. Lu, H.C. Peng, L. Protsailo, S. Guerrero, J.H. Park, X.H. Xia, J.G. Wang, M.J. Kim, Y.N. Xia, Nano Lett., 13 (2013) 3420-3425.

[16] J. Greeley, I.E.L. Stephens, A.S. Bondarenko, T.P. Johansson, H.A. Hansen, T.F. Jaramillo, J. Rossmeisl, I. Chorkendorff, J.K. Norskov, Nature Chem., 1 (2009) 552-556.

[17] M. Escudero-Escribano, A. Verdaguer-Casadevall, P. Malacrida, U. Gronbjerg, B.P. Knudsen, A.K. Jepsen, J. Rossmeisl, I.E.L. Stephens, I. Chorkendorff, J. Am. Chem. Soc., 134 (2012) 16476-16479.

[18] J. Zhang, H.Z. Yang, J.Y. Fang, S.Z. Zou, Nano Lett., 10 (2010) 638-644.

[19] B. Lim, M.J. Jiang, P.H.C. Camargo, E.C. Cho, J. Tao, X.M. Lu, Y.M. Zhu, Y.N. Xia, Science, 324 (2009) 1302-1305.

[20] J. Zhang, K. Sasaki, E. Sutter, R.R. Adzic, Science, 315 (2007) 220-222.

[21] C. Wang, D. van der Vliet, K.L. More, N.J. Zaluzec, S. Peng, S.H. Sun, H. Daimon, G.F. Wang, J. Greeley, J. Pearson, A.P. Paulikas, G. Karapetrov, D. Strmcnik, N.M. Markovic, V.R. Stamenkovic, Nano Lett., 11 (2011) 919-926.

[22] J. Snyder, T. Fujita, M.W. Chen, J. Erlebacher, Nat. Mater., 9 (2010) 904-907. 
[23] C. Chen, Y.J. Kang, Z.Y. Huo, Z.W. Zhu, W.Y. Huang, H.L.L. Xin, J.D. Snyder, D.G. Li, J.A. Herron, M. Mavrikakis, M.F. Chi, K.L. More, Y.D. Li, N.M. Markovic, G.A. Somorjai, P.D. Yang, V.R. Stamenkovic, Science, 343 (2014) 1339-1343.

[24] F. Maroun, F. Ozanam, O.M. Magnussen, R.J. Behm, Science, 293 (2001) 1811-1814.

[25] R. Burch, Acc. Chem. Res., 15 (1982) 24-31.

[26] M. Mavrikakis, B. Hammer, J.K. Norskov, Phys. Rev. Lett., 81 (1998) 2819-2822.

[27] C. Wang, N.M. Markovic, V.R. Stamenkovic, Acs Catalysis, 2 (2012) 891-898.

[28] C. Wang, M.F. Chi, G.F. Wang, D. van der Vliet, D.G. Li, K. More, H.H. Wang, J.A. Schlueter, N.M. Markovic, V.R. Stamenkovic, Adv. Funct. Mater., 21 (2011) 147-152.

[29] J. Kim, Y. Lee, S.H. Sun, J. Am. Chem. Soc., 132 (2010) 4996-4997.

[30] Q. Li, L.H. Wu, G. Wu, D. Su, H.F. Lv, S. Zhang, W.L. Zhu, A. Casimir, H.Y. Zhu, A. Mendoza-Garcia, S.H. Sun, Nano Lett., 15 (2015) 2468-2473.

[31] D.L. Wang, H.L.L. Xin, R. Hovden, H.S. Wang, Y.C. Yu, D.A. Muller, F.J. DiSalvo, H.D. Abruna, Nat. Mater., 12 (2013) 81-87.

[32] V.R. Stamenkovic, B.S. Mun, K.J.J. Mayrhofer, P.N. Ross, N.M. Markovic, J. Am. Chem. Soc., 128 (2006) 8813-8819.

[33] C.H. Cui, L. Gan, M. Heggen, S. Rudi, P. Strasser, Nat. Mater., 12 (2013) 765-771.

[34] Y.J. Wang, N.N. Zhao, B.Z. Fang, H. Li, X.T.T. Bi, H.J. Wang, Chem. Rev., 115 (2015) 3433-3467.

[35] W.T. Yu, M.D. Porosoff, J.G.G. Chen, Chem. Rev., 112 (2012) 5780-5817.

[36] J.K. Norskov, J. Rossmeisl, A. Logadottir, L. Lindqvist, J.R. Kitchin, T. Bligaard, H. Jonsson, J. Phys. Chem. B, 108 (2004) 17886-17892.

[37] J. Greeley, J.K. Norskov, J. Phys. Chem. C, 113 (2009) 4932-4939.

[38] J.R. Kitchin, J.K. Norskov, M.A. Barteau, J.G. Chen, Phys. Rev. Lett., 93 (2004).

[39] J. Greeley, J.K. Norskov, Surf. Sci., 592 (2005) 104-111.

[40] V. Stamenkovic, B.S. Mun, K.J.J. Mayrhofer, P.N. Ross, N.M. Markovic, J. Rossmeisl, J. Greeley, J.K. Norskov, Angew. Chem. Int. Ed., 45 (2006) 2897-2901.

[41] V. Ponec, G.C. Bond, Catalysis by metals and alloys, Elsevier, New York, 1995.

[42] G. Ertl, H. Knözinger, J. Weitkamp, Handbook of heterogeneous catalysis, VCH Wiley, Weinheim, 1997.

[43] S. Chen, H.A. Gasteiger, K. Hayakawa, T. Tada, Y. Shao-Horn, J. Electrochem. Soc., 157 (2010) A82-A97.

[44] B.L. Cushing, V.L. Kolesnichenko, C.J. O'Connor, Chem. Rev., 104 (2004) 3893-3946.

[45] R. Ferrando, J. Jellinek, R.L. Johnston, Chem. Rev., 108 (2008) 845-910.

[46] S.H. Sun, C.B. Murray, D. Weller, L. Folks, A. Moser, Science, 287 (2000) 1989-1992.

[47] C. Wang, M.F. Chi, D.G. Li, D. van der Vliet, G.F. Wang, Q.Y. Lin, J.F. Mitchell, K.L. More, N.M. Markovic, V.R. Stamenkovic, ACS Catal., 1 (2011) 1355-1359.

[48] D.G. Li, C. Wang, D. Tripkovic, S.H. Sun, N.M. Markovic, V.R. Stamenkovic, ACS Catal., 2 (2012) 1358-1362.

[49] J.L. Zhang, M.B. Vukmirovic, K. Sasaki, A.U. Nilekar, M. Mavrikakis, R.R. Adzic, J. Am. Chem. Soc., 127 (2005) 12480-12481.

[50] D. van der Vliet, D.S. Strmcnik, C. Wang, V.R. Stamenkovic, N.M. Markovic, M.T.M. Koper, J. Electroanal. Chem., 647 (2010) 29-34.

[51] P.E. Blöchl, Phys. Rev. B, 50 (1994) 17953-17979.

[52] G. Kresse, D. Joubert, Phys. Rev. B, 59 (1999) 1758-1775.

[53] B. Hammer, L.B. Hansen, J.K. Nørskov, Phys. Rev. B, 59 (1999) 7413-7421. 
[54] J.K. Nørskov, J. Rossmeisl, A. Logadottir, L. Lindqvist, J.R. Kitchin, T. Bligaard, H. Jónsson, J. Phys. Chem. B, 108 (2004) 17886-17892.

[55] Y. Ma, P.B. Balbuena, Surf. Sci., 602 (2008) 107-113.

[56] J. Rossmeisl, Z.W. Qu, H. Zhu, G.J. Kroes, J.K. Nørskov, J. Electroanal. Chem., 607 (2007) 83-89.

[57] J.A. Keith, G. Jerkiewicz, T. Jacob, ChemPhysChem, 11 (2010) 2779-2794.

[58] T. Bligaard, J.K. Nørskov, S. Dahl, J. Matthiesen, C.H. Christensen, J. Sehested, J. Catal., 224 (2004) 206-217.

[59] Y.J. Kang, J.B. Pyo, X.C. Ye, R.E. Diaz, T.R. Gordon, E.A. Stach, C.B. Murray, ACS Nano, 7 (2013) 645-653.

[60] H.F. Yin, C. Wang, H.G. Zhu, S.H. Overbury, S.H. Sun, S. Dai, Chem. Commun., (2008) 4357-4359.

[61] C. Wang, G.F. Wang, D. van der Vliet, K.C. Chang, N.M. Markovic, V.R. Stamenkovic, Phys. Chem. Chem. Phys., 12 (2010) 6933-6939.

[62] T.B. Massalski, H. Okamoto, P.R. Subramanian, L. Kacprzak, Binary Alloy Phase Diagrams, American Society for Metals: Materials Park, OH1990.

[63] D.F. van der Vliet, C. Wang, D.G. Li, A.P. Paulikas, J. Greeley, R.B. Rankin, D. Strmcnik, D. Tripkovic, N.M. Markovic, V.R. Stamenkovic, Angew. Chem. Int. Ed., 51 (2012) 3139-3142. [64] F. Abild-Pedersen, J. Greeley, F. Studt, J. Rossmeisl, T.R. Munter, P.G. Moses, E. Skulason, T. Bligaard, J.K. Norskov, Phys. Rev. Lett., 99 (2007).

[65] C. Wang, D.G. Li, M.F. Chi, J. Pearson, R.B. Rankin, J. Greeley, Z.Y. Duan, G.F. Wang, D. van der Vliet, K.L. More, N.M. Markovic, V.R. Stamenkovic, J. Phys. Chem. Lett., 3 (2012) 1668-1673.

[66] X.Q. Huang, Z.P. Zhao, L. Cao, Y. Chen, E.B. Zhu, Z.Y. Lin, M.F. Li, A.M. Yan, A. Zettl, Y.M. Wang, X.F. Duan, T. Mueller, Y. Huang, Science, 348 (2015) 1230-1234. 
Graphical Abstract
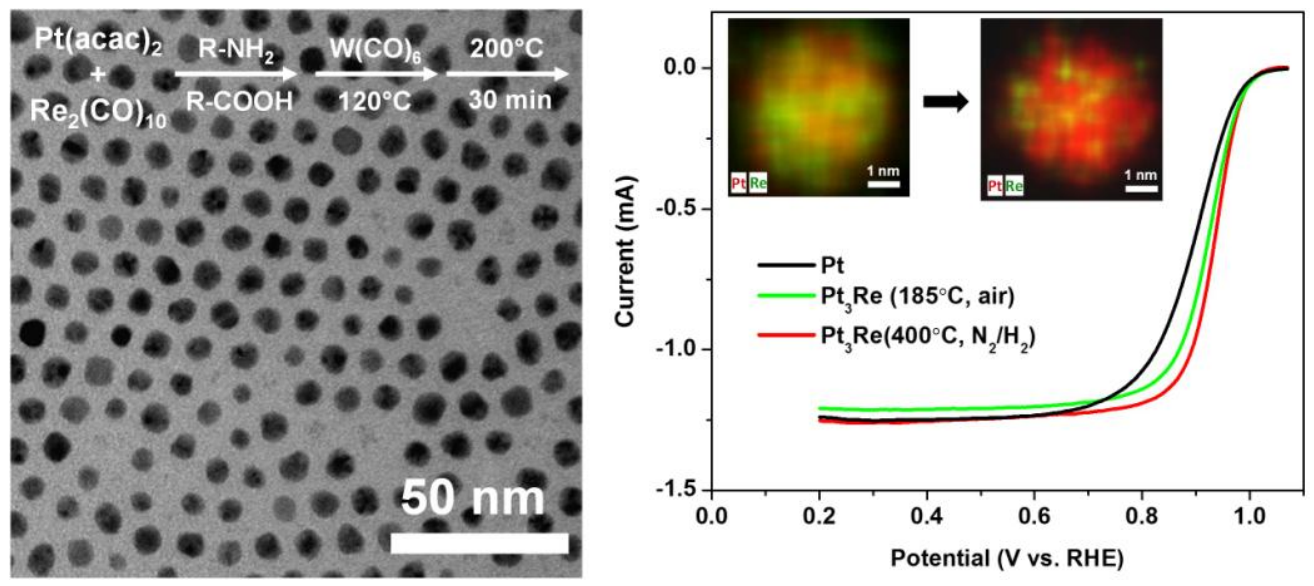